\title{
O psicólogo e algumas práticas no serviço público estadual de saúde
}

O lugar da Psicologia no contexto social, o papel do psicólogo na instituição hospitalar e a formação do psicólogo para novas atribuições e funçōes são analisadas através de uma pesquisa com psicólogos da área de saúde, levantando uma necessária discussão sobre este campo de trabalho. $O$ profissional de saúde deve se instrumentalizar com o saber, tendo sempre em vista o não-saber.

\section{Sonia Leite}

Professora Assistente da Universidade Estácio de Sá

Psicóloga do Instituto de Assistência dos Servidores do Estado do RJ

\begin{abstract}
"Quando chegamos aqui, o Hospital não estava esperando.
\end{abstract}

Não tínhamos sala, nem orientação.."

-"A sujeira, o descuido, o abandono com a saúde...as pessoas

aqui vivem uma condição desumana. Isso às vezes me paralisa,

me dá uma sensação de impotência"z

A questão da inserçāo do psicólogo na área de Saúde tem sido tema de reflexão e debate, especialmente nas duas últimas décadas $^{3}$. Estas discussões têm se intensificado a partir da década de $\mathbf{9 0}$ inserindo-se num campo mais amplo onde se destacam temáticas tais como, o /ugar da psicologia no contexto social, o papel do psicólogo nas instituicōes sociais, formação do psicólogo e as práticas sociais, etc. que retratam, em última instância, uma preocupação até certo ponto generalizada, com um quadro de crise cultural, social e ética que tem atravessado, não apenas, a sociedade brasileira com suas peculiaridades, mas também o mundo como um todo. São temáticas que revelam, enfim, a necessidade de reavaliarmos as relações do sujeito com a cultura, as possibilidades de reconstrução de novos valores norteadores da inserção do sujeito na sociedade e a revisão do próprio conceito de sujeito que tem direcionado as práticas sociais e as investigaçōes científicas que se iniciaram na Modernidade.

Acompanhando essas transformaçōes só- cio-culturais, verificamos 0 aparecimento de novos espaços para a prática da Psicologia, reveladores de novas tendências no próprio "perfil" profissional ${ }^{4}$. A entrada do psicólogo em novos campos de atuaçāo profissional tem exigido respostas para problemáticas até então desconhecidas no campo da formação acadêmica delineando-se, assim, questōes relativas à própria identidade profissional do psicólogo nos campos de trabalho recém construídos. Este fato tem, por outro lado, exigido das instituiçōes formadoras uma ampliação dos debates neste campo, além de novas propostas curriculares que acompanhem efetivamente as novas exigências do contexto social.

Além destes fatos, apontaremos algumas questōes mais específicas que impulsionaram nosso interesse nesta área de investigação:

a) Uma dada tendência ao imobilismo do sujeito profissional no Serviço Público, caracterizando-se como uma espécie de identificação com o aspecto instituído da instituiçãōo .

b) O fato, ainda presente, de uma predominância na formação do psicólogo de um modelo clínico-liberal-psicanalítico funcionando, algumas vezes como justificativa para 'marcar' uma impossibilidade de trabalho na área institucional pública.

c) Pesquisa realizada pelo CFP (Conselho Federal de Psicologia) ${ }^{6}$ em 1992, apontando uma tendência ao assalariamento profissional, tendo-se o Estado como um dos
'Este artigo sintetiza alguns dos dados obtidos na pesquisa denominada Análse das Práticas do Psicólogo no Servico Públlco Estadual de Saúde vinculada a UNESA (Universidade Estácio de Sá) que coordenei no período de março de 1994 à marco de 1995 e que contou com a participação dos seguintes auxiliares de pesquisa: Adriana SI/veira Pena, Nícla Maria M. Barroso, Rogério Scheer, Simone M. Delgado, Valéria Cristina G.C. Mendonça. ${ }^{2}$ Fala dos psicólogos entrevistados.

${ }^{3} \mathrm{U} m$ exemplo desta discussão encontramos na pesquisa realizada por um grupo de ps/cólogos do CRP-06 denominada: Estudo sobre a Inserção dos Psicólogos nas Unidades Báslcas de Saúde, publicada durante a gestão Movimento nOS CADERNOS CRP06, out/91.

${ }^{4} \mathrm{Com}$ relação ao tema ver: Psicólogo Brasileiro -

Construção de Novos Espaços, organizadores: Ana Lúcia Francisco, Carolina do Rocio Klomfahs, Nádia Maria Dourado Rocha, Campinas, Ed. Atomo, 1992.

${ }^{5}$ Esta constatação, a partir da minha própria insercão neste campo, serviu de temática para a elaboração de um trabalho denominado "O Vínculo SujeitoInstituição Pública ou o TempoMorto nas

Burocraclas"apresentado em set/ 94 no Seminário "O Mal-Estar do Corpo no Encontro como Trabalho"na ENSP (Escola Nacional de saúde Pública). 


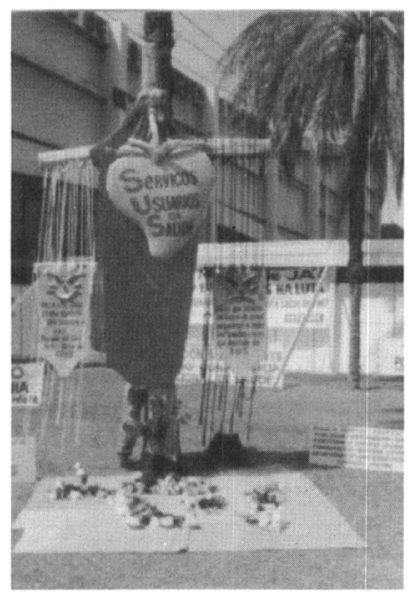

$10^{a}$ Conferência Nacional de Saúde principais empregadores nos últimos anos.

d) Realização de concursos para a área da Saúde Pública e a ofícialização de estágios curriculares, a partir de 1991 (Estado).

e) Um interesse no que diz respeito à teoria da constituicão do sujeito, seus contornos na relação sujeito-cultura e mais especificamente no que diz respeito à relação sujeito-instituição.

A amostra escolhida constou de 34 (trinta e quatro) profissionais dos quais 31 (trinta e um) do sexo feminino e 3(três) do sexo masculino, lotados nas Unidades Médicas do Estado do Rio de Janeiro ${ }^{7}$ aprovados em concurso público em 1990, ou seja, à época da pesquisa os profissionais acumulavam em média 3(três) anos de atividades profissionais. O objetivo principal era o de cartografar as atividades que estariam sendo realizadas, supondo-se do ponto de vista da formação profissional uma predominância no campo clínico-liberal e sabendo-se, ainda, que na maioria das Unidades onde os profissionais teriam sido lotados, não havia uma tradição de trabalho profissional, sendo que, em alguns casos, o psicólogo entrava para os quadros da instituição, pela primeira vez.

A seguir, delinearemos os principais pontos encontrados ao longo das etapas desta pesquisa ( Análise Documental e Entrevistas) e algumas reflexōes e conclusões a que fomos conduzidos durante este processo.

Com relação à primeira etapa desta investigação - a análise documental - foi possível constatarmos, a partir de contatos com a Secretaria de Saúde, através da Comissão de Saúde Mental do Estado, a inexistência de Programas ou Planejamentos prevendo a atuaçāo do psicólogo nas Unidades Médicas do Estado ${ }^{8}$ (Hospitais Gerais e Institutos), sendo que o único programa existente diz respeito à atuação nas Unidades Psiquiátricas (Hospitais, Centros e Postos), elaborado em $1986^{9}$. Este programa, vinculado à chamada Luta Anti-Manicomial, norteou a abertura de um concurso público realizado neste período (1986). O que ficou evidenciado foi um verdadeiro desinteresse pela atuação $p s i$ nos Hospitais Gerais e Institutos, ou seja, quando se fala em saúde mentalo que está em foco é o chamado paciente psiquiátrico e, conseqüentemente, a atuação profissional nas Unidades Psiquiátricas ${ }^{10}$. $O$ concurso de 1990 ocorreu a partir de negociações diretas do Sindicato dos Psicólogos e do CRP 05 (Conselho Regional de Psicologia) ${ }^{11}$ com o representante da Secretaria de Saúde daquele período.

A partir das entrevistas realizadas com os profissionais foi possível obter informaçōes sobre dois aspectos: formação profissional e contexto de trabalho.

\section{FORMAÇÃO PROFISSIONAL: A/gumas Questöes}

Os psicólogos entrevistados são oriundos das seguintes faculdades de psicologia:

Faculdade Celso Lisboa; Faculdades de Humanidades Pedro II (FAHUPE); Universidade Estadual de Londrina(UEL); Universidade do Estado do RJ(UERJ); Universidade Federal Fluminense(UFF); Universidade Federal do RJ(UFRJ);Pontifícia Universidade Católica do RJ (PUC/RJ). Do total, $68,5 \%$ dos profissionais são oriundos da universidade pública, com maior concentraçāo na UFRJ(Universidade Federal do Rio de Janeiro). Os $41,5 \%$ restantes oriundos da universidade privada com maior concentração na USU(Universidade Santa Úrsula).

Foi possível verificar uma concentração do ano de formaçāo dos profissionais entre 1985 à 1988 (61,7\%) sendo que o maior índice foi em 1988, ou seja, a maior parte dos profissionais eram recém formados à época do concurso, caracterizando este tipo de concurso como uma verdadeira opçāo de campo de trabalho.

Identificamos uma concentração de cursos, grupos de estudo, durante a formação profissional, no campo do saber psicanalítico $(55,8 \%)$ e estágios na área de saúde mental/psiquiatria $(61,7 \%)$. Apenas $17,6 \%$ dos entrevistados tiveram experiências de estágios em Hospitais Gerais.

Estes últimos dados foram apontados como geradores de um certo descompasso entre instrumental teórico dominante (psicanálise, fundamentalmente) e a realidade de trabalho. Além disso, diante da impossibilidade de uma "verdadeira" prática psicanalítiça atribuída a entraves institucionais o que verificamos, de fato, foi uma predo- 
minância do discurso psicanalítico. ${ }^{12}$ Com relação as tendências em termos de pós-graduaçāo, $55,8 \%$ dos entrevistados procuraram cursos de especializaçāo na área de saúde/saúde mental. Verificamos um interesse significativo por cursos de formaçāo em Psicanálise, principalmente, e outros tais como, Gestalt-Terapia, Linha Rogeriana, Existencialismo e Arteterapia. Este tipo de opção pode ser reportado ao fato de que dos 34 (trinta e quatro) entrevistados, 26 (vinte e seis), ou seja, 76,44\% dos profissionais, mantêm como atividade paralela a clínica particular.

Verificamos, ainda, uma grande incidência em duas questōes apontadas pelos entrevistados como fundamentais para a prática profissional neste campo:

- leituras e estudos objetivando a construção do saber e da prática;

- contatos com outros profissionais da área visando romper o isolamento no campo de trabalho.

\section{CONTEXTO DE TRABALHO: Atravessa- mentos e Demandas}

Quanto as principais características do contexto de trabalho circunscrevemos dois tipos principais de atravessamentos ${ }^{13}$ :

- do campo médico-psiquiátrico;

- da burocracia pública.

\section{I) o Campo Médico-Psiquiátrico}

A questão do atravessamento do campo médico-psiquiátrico diz respeito à constituição histórica do próprio saber médico e suas conseqüências no que diz respeito à função do campo hospitalar daí por diante.

Como nos mostra Foucault (1984), o Hospital não foi desde sempre instituição médica com fins terapêuticos. Antes do séc.XVIII, o Hospital era, fundamentalmente, lugar de recolhimento e exclusão, com o objetivo de transformação espiritual de loucos, doentes, prostitutas, pobres, etc. Um "morredouro", local de "libertação das almas" dirigido por uma ordem religiosa. Sendo assim, o pessoal atuante nos Hospitais tinha, fundamentalmente, uma funcão filantrópica, caritativa (religiosa ou não). $\hat{E}$ somente numa tentativa de anulação dos

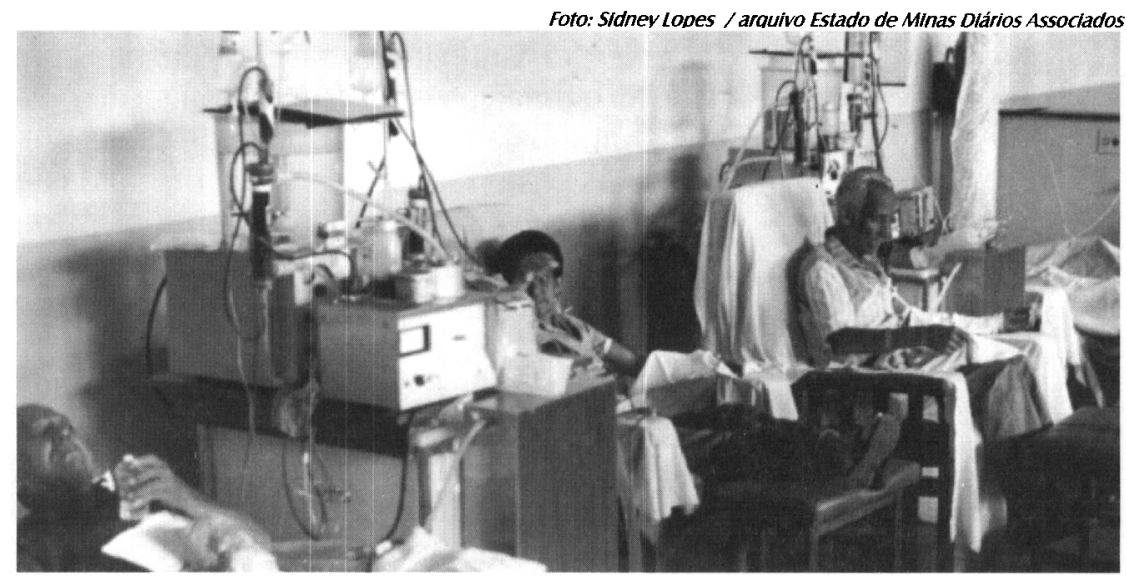

efeitos "negativos" do Hospital (presença de doencas passíveis de transmissāo e "locus" de desordem social) que este passa a ser visto como espaço terapêutico. saneador, tendo como eixo central a idéia de disciplina. Nesta perspectiva, a partir do séc. XVIII, o médico torna-se o principal responsável pela organização hospitalar e pelo funcionamento econômico. ocupando um lugar privilegiado na hierarquia institucional.

Neste processo de organização institucional paulatinamente se constituirá a chamada Medicina Especial que herdará dos higienistas e filantropos a proposta de reforma social, atuando diretamente em termos de "problemática social" e que terá no louco e na loucura seus principais representantes. São, fundamentalmente, os psiquiatras que representarāo o saber e a prática capazes de combater e anular as desordens na organizaçāo da sociabilidade. Ou seja, a Medicina Especial, antes de ser uma medicina orgânica, é uma medicina social.

Verificamos, então, a prática médica instituindo dois tipos de objetos como conseqüência de uma "fratura" instaurada historicamente. Temos, a partir daí, uma Medicina Geral e o objeto corpo (racionalidade anatomopatológica) indicativa de uma preocupação cientificista da medicina e, por outro lado, a constituição do objeto mente/alma para uma Medicina Especial com características de cunho filantrópico (racionalidade psicológica). Configurar-se-á, em torno deste último eixo, uma linha de "tratamento moralizante", visando a integraçāo/adaptaçāo do sujeito ao campo social (Birman, 1980). Há, assim, uma tensão que se estabele-
'Jornal Federal - Conselho Federal de Psicologia - Ano VIII, n.33, jan/abr de 1993.

'Trata-se de 18 (dezoito) Hospitais Estaduais dos quais 4 (quatro) são Hospitais Colônias hanseniase $e$ o outro de doenças infecto-contagiosas), sendo os demais Hospitais Gerais e Institutos Especializados (Hematologia, Infectologia, Cardiologia e DiabetesEndocrinologia).

${ }^{8}$ Durante as entrevistas obtivemos alguns programas elaborados pelos próprios profissionais a partir da inserçào em suas Unidades.

${ }^{9}$ Programade Saúde Mental Secretaría do Estado de Saúde e Higiene

Departamento Geral de Programs Especiais - Rio de Janeiro/1986.

${ }^{10}$ Das 18 (dezoito) Unidades Médicas que se constituiu como amostra da pesquisa apenas duas referem-se a Hospitais Psiquiátricos: Hospital Estadual Psiquiátrico (HEP) e o Hospital Estadual Vargem Alegre (HEVA). (dois psiquiátricos, um de 
ce entre Medicina Geral e Medicina Especial e uma verdadeira desvalorização deste último campo em função de "suas precárias bases científicas", cuja proposta de atuação o aproximava dos antigos filantropos.

Podemos supor que, hoje, a entrada do psicólogo no Hospital Geral tende a suscitar e a reativar algumas dessas contradições. Uma das principais queixas, por exemplo, dos psicólogos pode ser apontada exatamente na direção de uma não valorização e de um não reconhecimento de suas atividades no campo de trabaIho, pela maioria dos médicos voltados para questōes sintomáticas e orgânicas. O que podemos verificar ao longo da história é a produçāo de uma oposiçāo entre dois modelos médicos: um baseado numa racionalidade anatomopatológica e outro baseado numa racionalidade psicológica.

Birman (1980) mostra como, posteriormente, na década de 50 , haverá uma tendência de redefinição da medicina somática pela psiquiatria, devido à incorporação do discurso psicanalítico, fundamentalmente, ou do que ele denomina dispositivo das inter-relacōes pessoais. Um dos paradigmas deste dispositivo é a proposta de humanização da medicina a partir da ênfase na relação médico-paciente e da chamada medicina psicossomática. Apesar de $o$ autor fazer referência a este processo como algo que já teria se instaurado de forma dominante, ou seja, a passagem ou transformação do campo médico em campo médico-psicológico, encontramos a partir desta pesquisa outros indicativos.

o que parece, ainda, predominar é uma atuação por "áreas", onde caberia ao médico o "orgânico" e ao psicólogo o "psíquico". Isto levou-nos a considerar que o chamado campo médico atualizado nas instituições públicas tende a se caracterizar prioritariamente na chamada abordagem anatomopatológica, como afirma uma entrevistada:

-... O médico cuida da parte orgânica...quando eles precisam de ajuda nos pedem."
Esta questão associada a outras características como a pobreza, o abandono e o descaso político a que são relegadas estas instituições tende a transformar os Hospitais Estaduais algumas vezes em verdadeiros "morredouros", como bem caracterizou Foucault ao falar do Hospital do séc. XVIII. Encontramos algumas demandas institucionais predominantes dirigidas aos psicólogos. Por um lado, um tipo de demanda que denominamos de emergencial-circunstancial relacionada a situaçōes de "crise" institucional visando, em última instância, a manutençāo da ordem hospitalar; ou seja, o que se atualiza nestes espaços é uma proposta de disciplinarização. É preciso enfatizar que este tipo de demanda surge quando o médico "não dá conta", o que evidentemente carrega de tensão a relaçāo entre esses profissionais.

Segundo a expressão dos entrevistados eis alguns exemplos de demandas dirigidas aos psicólogos:

-"Calar a boca do paciente indócil.."

-"Colocar ordem na enfermaria..."

-"Agir quando o comportamento do paciente impede o trabalho da equipe."

Por outro lado, por parte dos usuários das Unidades verifica-se uma demanda de atencão e afeto ou ainda demanda de escuta que, neste último caso, mais do que um pedido de "escuta psicanalítica", como pareceria à primeira vista, trata-se de um simples pedido de reconhecimento, enquanto cidadão, muitas vezes negado pelas condiçōes precárias do atendimento médico.

Segundo uma entrevistada, a princípio os pacientes não sabem que existe psicologia, mas a seguir a demanda fica clara:

\section{-"Chegou alguém que finalmente me es- cuta..."}

Esta situação, como nos indicam alguns profissionais, parece apontar algumas vezes uma ocupaçāo de espaço institucional muito mais de caráter filantrópico do que propriamente profissional por parte dos psicólogos.

Outro tipo de demanda bastante freqüen- 
te é de psicoterapia por parte dos funcionários das Unidades e de seus familiares, levando-nos a considerar as condiçōes da própria organização do trabalho que facilitariam a produção deste tipo de demanda.

\section{II) A Burocracia Pública}

Quanto ao atravessamento burocrático, uma das características freqüentes se situa na propagação de uma dada subjetividade que se expressa no profissional como falta de vontade ou de desejo. Uma maneira de compreendermos os efeitos deste tipo de atravessamentoé a partir da questão da temporalidade (Leita, 1994). O que podemos observar nas instituições públlcas é que o tempo enquanto devir, movimento, parece ser substituído por um tempo pré-visto, pré-determinado, que submete as açōes dos sujeitos. Tende-se, então, a viver num passado idealizado ("Antigamente o serviço público funcionava...") ou num futuro previsto que pode ser representado pela expectativa dos benefícios (licença, férias, aposentadoria, etc.) permeados de características vitalícias. Esta parece ser uma forma de escapar ao mal-estar produzido na relaçāo sujeito-instituição pública. A temporalidade assim absolutizada (Virilio, 1983), desvincula-se do cotidiano e do próprio ato de trabalho, ocorrendo uma forma de alienaçāo da subjetividade. O setor público ao se revestir, ainda, como "Terra de Ninguém" (Costa, 1991) produz uma espécie de "autonomia forçada" onde o "fazer ou não-fazer" torna-se indiferente e o não-reconhecimento do trabalho seu fundamento.

\section{DESDOBRAMENTOS: Identidade e Mo- delos na Formação do Psicólogo}

Finalizando, gostariamos de apontar algumas questōes que se desdobram a partir da inserção do psicólogo neste campo de atuação:

- discussões sobre a identidade profissional;

- a questāo do modelo médico-psiquiátrico na formação do psicólogo;

- o fator da preponderância do discurso psicanalítico na formação do psicólogo banalizando, algumas vezes, a própria prática psicanalítica;

- os limites e as possibilidades no campo da formação profissional no sentido da instrumentalização do sujeito para a produção de movimentos no campo profissional, onde as ações possibilitem a desconstrução do instituído, a produção do desejo e a invenção de novas intervençōes, como ilustra a fala de um entrevistado:

\section{- "...A formação do psicólogo também é uma dificuldade, pois não dá conta do tra- balho no Hospital...é preciso ampliar esta noção de saúde mental. Em função do despreparo as pessoas acabam saindo, pois o psicólogo ou fica no lugar do para- médico ou não tem lugar. Falta, então, uma identidade do psicólogo no espaço hospitalar".}

O espaço hospitalar, antes de mais nada, coloca em questão a Identidade profissionaldo psicólogo. Certas faltas sobressaem e, diante deste vazio, buraco, como se referem alguns profissionais, surgem condiçōes tanto para um verdadeiro imobilismo, quanto para novas construçōes, tentativas efetivadas no próprio ato de trabalho, como ilustra a fala de uma entrevistada:

-"A Oficina tinha como objetivo discutir o que era o trabalho na área de Saúde $e$ também ser um espaço alternativo para os pacientes. Surgiram questōes sobre como trabalhar aqui e o esfacelamento das funçōes, cargos e trabalho."

O próprio conceito de identidade pode nos levar a pensar algumas questōes. Segundo Aurélio (1993) uma das definições possíveis de identidade é o "conjunto de caracteres próprios e exclusivos", neste caso, de uma dada profissão, ou ainda como afirma Clampa (1989): "...manifestação de um ser idêntico a si mesmo na sua permanência e estabilidade". $O$ espaço hospitalar ao atualizar o campo médíco-psiquiátrico demanda do psicólogo a manutençāo de uma dada identidade $e$ simultaneamente produz um verdadeiro questionamento dos lugares estabelecidos, em função da heterogeneidade de acontecimentos que este espaço possibilita.

Isso nos leva a reconsiderar o próprio con-

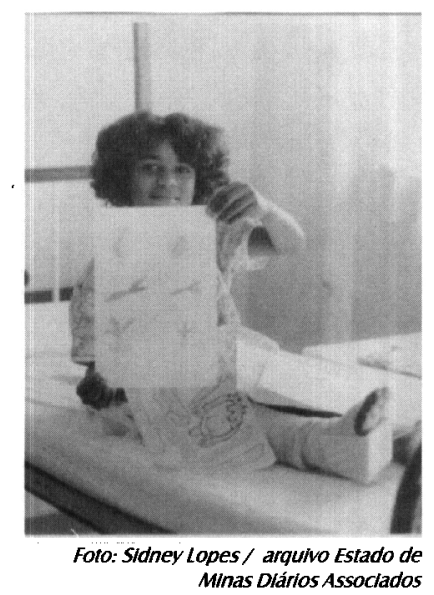

Minas Diários Assoclados 
ceito de identidade no sentido de aí incluir, de uma maneira mais radical, a relação do sujeito com a cultura, com o campo social, onde a idéia de transformação e de construcão contínua se viabilize e onde o sujeito profissional ao afetar-se pela realidade crie possibilidades de (re)construí-la sob novos parâmetros. Isso significa, por exemplo, que apesar de a prática do psicólogo se "localizar" num Hospital, não, necessariamente, deverá pautar-se no modelo médico de entendimento da assistência, de modo a não proceder a uma naturalização das demandas institucionais ou dos usuários, criando outros modos de intervenção na realidade.

Apesar de alguns entrevistados afirmarem não ter expectativas de mudança com relação ao trabalho realizado, outros consideraram que uma transformação das práticas realizadas se estabeleceria a partir da promoção de discussōes e troca de experiências com outros profissionais. Este parece ser um caminho favorecedor da delimitação de um lugar neste campo profissional evitando-se um papel de disciplinarização institucional.

Procuramos, ao longo deste relato, caracterizar algumas condições que circunscrevem as práticas do psicólogo no contexto hospitalar público. Nosso intuito foi o de contribuir para uma discussão sobre este campo de atuação procurando romper, simultaneamente, com um certo isolamento que como profissionais somos muitas vezes conduzidos.

Gostaríamos de assinalar que consideramos a formação profissional espaço privilegiado para o fornecimento de certos instrumentos ao modo da caixa de ferramentas deleuzia$n a^{14}$ onde o saber não seja simplesmente adquirido, mas fundamentalmente questionado e relativizado, criando-se condiçōes para formas variadas de inserção profissional.

Para isso é necessário que o profissional se instrumentalize com o saber tendo sempre em vista o não-saber, ou seja, o fato de que nenhum conhecimento é capaz de totalizar o homem, pois o que sempre se anuncia no horizonte é o viés do desconhecimento.

Assim consideramos, por exemplo, que o saber psicanalítico no campo médico-psicológico deverá funcionar menos no sentido de uma simples aplicaçāo teórico-técnica e mais no sentido do fornecimento de um direcionamento ético que valorize o singular de cada situação, onde as rupturas e a criação encontrem expressão questionando a mera reprodução de modelos. Ou seja, mais do que valorizar a saúde, trata-se aqui de resgatar continuamente o existir enquanto processo nos contextos institucionais, onde os discursos dos sujeitos possam encontrar expressão e reconhecimento apesar dos /ugares instituidosna configuração institucional, como afirmam nossas entrevistadas:

-"...A instituição espera um trabalho de adequação, integração, controle, e isso se choca como trabalho de potencializar o sujeito nāo centralizando na doenç..."

-"O que é possível ser feito? Uma atuação do psicólogo que não se

cristalize na lógica da instituiçāo, não se deixando capturar, aderindo a crítica...".

\section{Referências Bibliográficas}

Birman, J. (1980) . Enfermidade e Loucura Rio de Janeiro, Ed. Campus.

Ciampa, A.C. (1989) . Identidade in: Psicologia Social o Homem em Movimento São Paulo, Ed. Brasiliense.

Costa, J.F. (1991). Psiquiatrla Burocrática - Duas ou Três Colsas que sel dela in: Clínica do Social Sāo Paūo, Ed. Escuta.

Figueiredo, A.C.C. (1984) . Estratéglas de Difusão do Movimento Psicanalítlco no Rlo de Janeiro PUC/RJ, Tese de Mestrado.
Foucault, M. (1984) . O Nascimento do Hospital In: Microfísica do Poder Rio de Janeiro, Ed. Graal.

Leite, S.C. (1994) . A Questão do Vínculo SujeitoInstituição Pública ou o Tempo Morto nas Burocracias Rio de Janeiro, No Prelo, ENSP (Escola Nacional de Saúde Pública)

Virilio, P. (1983) . Guerra Pura - A Militarização do Cotidiano São Paulo, Ed. Brasiliense. 